\title{
Tangential Algorithm for Calculation of the Fractal Dimension of Kidney Tubuli Sections
}

\author{
Algoritmo de Tangencialización para el Cálculo de la \\ Dimensión Fractal de Túbulos Renales Seccionados
}

Julio Gil; Miguel Gimeno; Jesús Laborda; Javier Nuviala \& Ignacio Belanche

\begin{abstract}
GIL, J.; GIMENO, M.; LABORDA, J.; NUVIALA, J. \& BELANCHE, I. Tangential algorithm for calculation of the fractal dimension of kidney tubuli sections. Int. J. Morphol., 24(1):31-34, 2006.

SUMMARY: We have developed a new algorithm to calculate the fractal dimension of dog kidney proximal convoluted tubule section. This algorithm is intermediate between box-counting and perimeter-stepping algorithms. The result of this new algorithm and correlations found between fractal dimensions and other Euclidian values of these tubuli, suggest that this algorithm is adequate to calculate fractal dimensions by points.
\end{abstract}

KEY WORDS: Fractal; Kidney; Proximal convoluted tubuli.

\section{INTRODUCTION}

An object is fractal if it has got fractal dimension (Mandelbrot, 1985).

The nephron is the structural unit responsible for the main functions of the kidneys. The nephron has two components, the glomerulus and the renal tubule. Renal tubule has several components, one of which is the proximal convoluted tubule (Fig. 1).

To know if proximal convoluted tubuli are fractals opens the possibility of being able to characterize them by means a unique and objective value (Mandelbrot; Gil et al., 1992), that probably could have some taxonomic value.

We developed a new algorithm to calculate the fractal dimension of convoluted objects, like the outline images of a serially sectioned proximal convoluted tubule. The resulting algorithm is intermediate between box-counting and perimeter-stepping algorithms (Cross, 1994).

\section{MATERIAL AND METHOD}

For the purpose of this study we have used one crossbred male adult dog weighing $20 \mathrm{~kg}$, provided by the local Service of Animal Protection. The animal was euthanatized by mean the protocol approved by Zaragoza University Animal Care Committee.

Afterwards, the abdominal cavity was opened and the two kidneys were extracted and fixed. The fixation was carried out at room temperature, for seven days, with a standard fixative solution of formol $10 \%$. Later, pieces of renal tissues were handed following conventional procedures for optical microscopy. Sections $5 \mu \mathrm{m}$ thick were stained with Hematoxilin and Eosine.

Eighteen X400 optical microscopy pictures showing proximal convoluted tubuli like in Fig. 1. The pictures were digitalized by means of a Hewlett Packard ScanJet IIc. Each picture was obtained from different sites within the two kidney cortexs. Coordinates of the outline image of each proximal convoluted tube were obtained with Atlas*MapMaker 4.03 program (Strategic Mapping Inc).

We calculated the fractal dimension of the proximal convoluted tubule with a computer program designed by us on Think Pascal 4.0.2 (Symantec Corp.). Our calculus algorithm uses tangential segments (Fig. 2). 
Results were plotted in log-log graphs. Fractal dimension is the negative slope of the regression line calculated from de plot of log-log graph (end of Fig. 2).

Graphics and statistical calculations were made with StatView SE+ (Abacus) and Cricket Graph III (Computer Associates International Inc), programs. All computer tasks were made with a Macintosh computer.

The algorithm. This new algorithm is intermediate between box-counting and perimeter-stepping algorithms.

At first, we placed the middle point of a segment (dividers), tangent on the top point of the outline image of a proximal convoluted tubule. Next segment is placed with its initial extreme on the final one of the previous segment, and rotating the dividers about this point until the segment is tangent to the outline image (Fig. 2).

We iterated this step until one of the dividers crossed the first segment. Math calculations reduced the length of first and last segments, from the intersection point between theese segments. Finally, the outline image ended inside of a polygon (Fig. 2).

This procedure is iterated 30 times, with segments becoming shorter (Fig. 2).

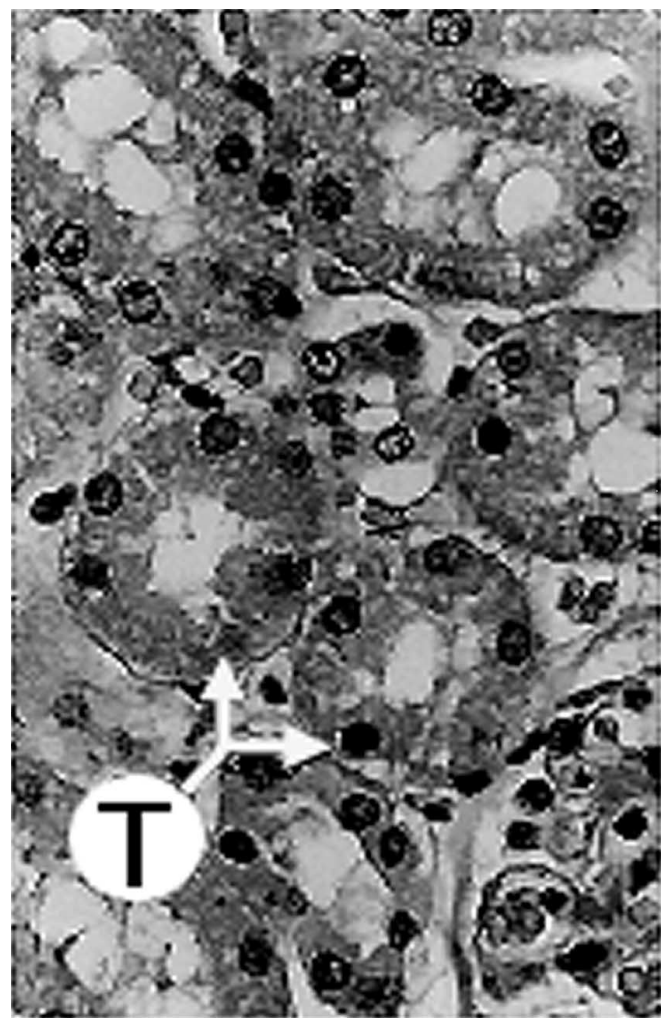

Fig. 1. Cortex of kidney dog. T=Proximal convoluted tubuli. HE. X400.

\section{RESULTS}

Both of the dog kidneys used in this study showed a normal, healthy appearance. The eighteen proximal convoluted tubuli analyzed and the calculations of their fractal dimensions, perimeters and areas, are shown on Table I.

The concept of fractal dimension encloses a certain complexity because of its nature is far of our usual experience in perception of the space. With the aim of finding some possible relationships with other measures which we are usually more accustomed with, we have calculated a statistical index on fractal dimensions and correlation coefficients between fractal dimensions, areas and perimeters, as can be seen on Tables II and III, respectively. In the log-log graphs the $\mathrm{X}$ axis is the log length segment. The $\mathrm{Y}$ axis is the log number of perimeter.

Fractal dimension is the negative slope of the regression line calculated from de plot of log-log graph (end of Fig. 2).

Table I. Set of measurement obtained from eighteen proximal convoluted tubuli outline images. Fractal Dim by Tangency.

\begin{tabular}{ccc}
\hline $\begin{array}{c}\text { Fractal Dim by } \\
\text { Tangency }\end{array}$ & Perimeter & Area \\
\hline 0.9228 & 633 & 35508 \\
0.7000 & 597 & 32605 \\
0.9553 & 604 & 34620 \\
0.9149 & 566 & 32290 \\
0.8270 & 646 & 35167 \\
0.9162 & 583 & 33393 \\
0.9364 & 604 & 34569 \\
0.9417 & 614 & 35232 \\
0.8921 & 634 & 41007 \\
0.9053 & 614 & 34880 \\
0.8918 & 645 & 38688 \\
0.8559 & 599 & 33548 \\
0.9598 & 649 & 39484 \\
0.8423 & 540 & 30375 \\
0.8930 & 702 & 43586 \\
0.8148 & 625 & 36299 \\
0.9624 & 562 & 31341 \\
0.9698 & 629 & 38267 \\
\hline
\end{tabular}

Table II. Statistic calculations on fractal dimensions

\begin{tabular}{cc}
\hline & Our algorithm \\
COUNT & 18 \\
MEAN & 0.9 \\
MAXIMUM & 1 \\
MINIMUM & 0.7 \\
RANGE & 0.3 \\
STD.DEV. & 0.1 \\
STD. ERROR & 0.16 \\
VARIANCE & 0.004 \\
\hline
\end{tabular}




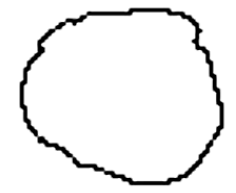

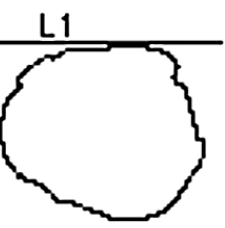
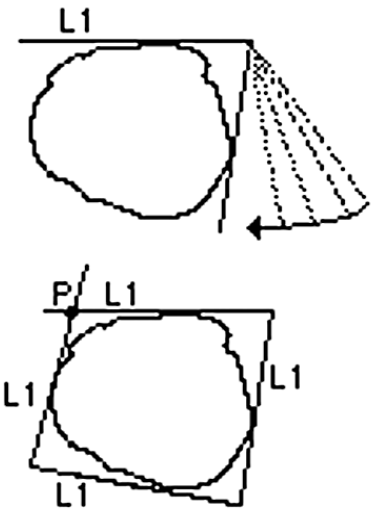

\begin{tabular}{|c|c|}
\hline $\begin{array}{c}\text { MEASURE } \\
\text { UNIT }\end{array}$ & PERIMETER \\
\hline L1 & P1 \\
L2 & P2 \\
$\cdot$ & $\cdot$ \\
L30 & P30 \\
\hline
\end{tabular}

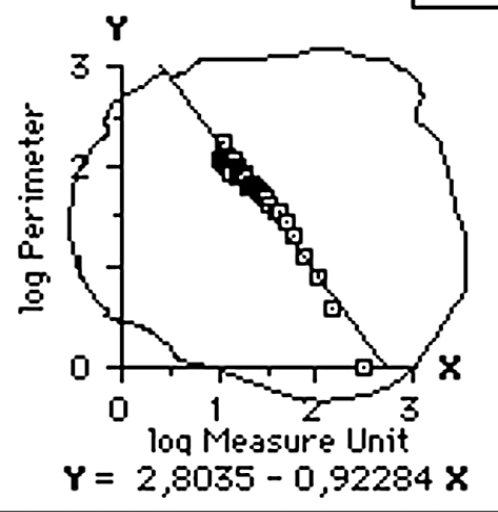

$\mathbf{Y}=2,8035-0,92284 \mathbf{X}$

\section{Outline image of a Proximal}

Convoluted Tubule

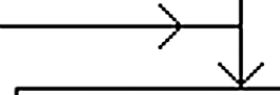

L1 is the first tangent lenght.

It is placed on the top point of the figure

Next tangent seament is placed with its initial extreme following the final extreme of the pevious segment.

The final extreme of this new segment, is placed according to the angle between this segment and the previous segment. At step one, there is a wide angle. At the following steps, this angle decreases, so one point of the segment is tangent to the outline image.
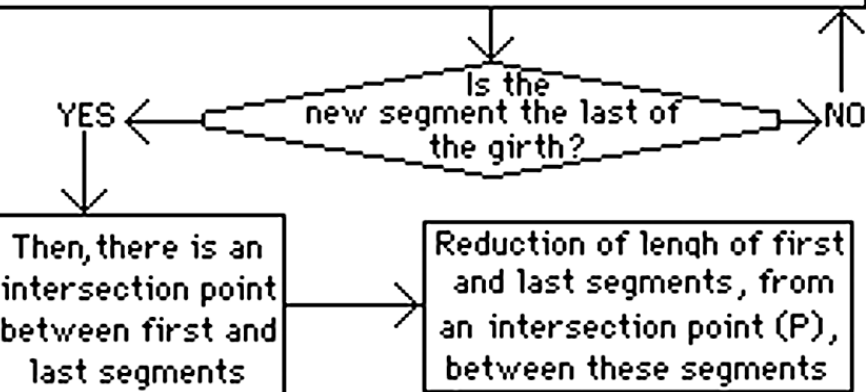

last segments these segments

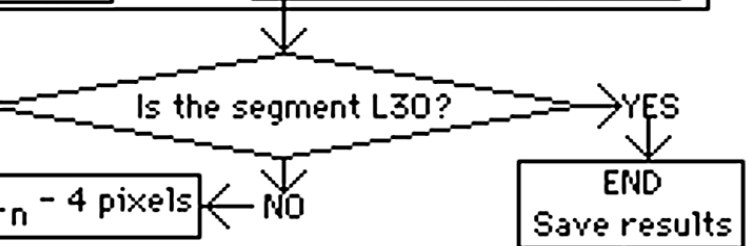

Then, $L_{(n+1)}=L_{n}-4$ pixels $<N \frac{1}{0}$

Save results

Fig. 2. Method and algorithm.

\section{DISCUSSION}

Table III. Correlation coefficient.

Between Our algorithm

Dim.Fractal and Perimeter $\quad 0.1$

Dim. Fractal and Area $\quad 0.2$

Perimeter and Area
0.2
In the kidney cortex, proximal convoluted tubuli are distinguished by the brush borders of their epithelial cells and somewhat scalloped appearance of the apical surface of their cells when the latter are seen in profile (Bacha \& Wood, 1990). 
Fractal dimension gives an index of the space-filling capacity of an object. An objetc is fractal if it has fractal dimension (Mandelbrot).

The fractal dimension of the proximal convoluted tubule of the dog kidney that we have obtained is $0.9 \pm 0.15$ (Table. II). Thus, dog kidney proximal convoluted tubuli are fractals. Calculation of the fractal dimension of the proximal convoluted tubule in this study has been carried out using optic microscopy pictures with magnification X400. In spite of this, a further advantage of the procedure is that, in almost all circumstances, the fractal component of the dimension is retained when a fractal object is projected to a lower order dimension (Falconer, 1993).

On the other hand, fractal dimension must be greater than Euclidian dimension (De Guzman et al., 1993) The fractal dimension of the convoluted butuli calculated by means of the new algorithm is lower and different than 1, that is its Euclidian dimension. This lower fractal dimension indicates that the new algorithm does not measure probably the linear dimension of the outline, but its point dimension. The correlation found between fractal dimension and perimeter or area of the proximal convoluted tubuli of the dog kidney (Table III), supports the idea of some characteristic natural background that may be expressed by mean fractal geometry of this organ.

A number of models have been developed to analyze morphological changes within organs (Caruthers \& Harris, 1994; Meléndez et. al., 1999). Fractal analysis based on microcomputer studies of image systems may provide many advantages to the understanding of the complex microscopical arrangement of natural objects (Cross \& Cotton, 1992). On this way, box-counting algorithm its best than our new algorithm to determine the linear fractal dimension of convoluted objects, like outline image of a proximal convoluted tubuli section from dog kidney.

\section{ACKNOWLEDGEMENTS}

Angel Hernando for his helpful on dog handing.

GIL, J.; GIMENO, M.; LABORDA, J.; NUVIALA, J. \& BELANCHE, I. Algoritmo de tangencialización para el cálculo de la dimensión fractal de túbulos renales seccionados. Int. J. Morphol., 24(1):31-34, 2006.

RESUMEN: Hemos desarrollado un nuevo algoritmo para calcular la dimensión fractal de las secciones de los túbulos contorneados proximales del riñón de perro. Este algoritmo es promedio de los que emplean el recuento de cajas y la medida del perímetro. El resultado de las medidas con este nuevo algoritmo y las correlaciones encontradas entre sus valores de dimensión fractal y otros valores euclidianos de dichos túbulos, sugieren la adecuación de método para calcular la dimensión fractal referida a puntos.

PALABRAS CLAVE: Fractal; Riñón; Túbulo contorneado proximal.

\section{REFERENCES}

Bacha, W. J. \& Wood, L. M. Color Atlas of Veterinary Histology. Lea \& Febiger. Philadelphia, London, 1990.

Caruthers, S. D. \& Harris, T. R. Effects of pulmonary blood flow on the fractal nature of flow heterogeneity in sheep lungs. Am. Physiological Society., 161:7567, 1994.

Cross, S. S. \& Cotton, D. W. K. The fractal dimension may be a useful morphometric discriminant in histopathology. J. Path., 166:409-11, 1992.

Cross, S. S. The Application of Fractal Geometic Analysis to Microscopic Images. Micron., 25(1):101-3, 1994.

De Guzmán, M.; Martín, M. A.: Morán, M. \& Reyes, M. Estructuras Fractales y sus Aplicaciones. Labor, Madrid, 1993.

Falconer, K. Fractal Geometry: Mathematical Foundations and Applications. John Wiley, Chicester, 1993.
Gil, J. G.; Gimeno, M. G. \& Murillo, N. L. The arterial pattern and fractal dimension of the dog kidney. Histol Histopath., 7:563-74, 1992.

Meléndez, R.; Meléndez-Hevia, E.; Canela, E. I. The Fractal Structure of Glycogen. Biophysical J., 77:1327-32, 1999.

Mandelbrot, B. Los objetos fractales. Tusquets, Barcelona, 1985.

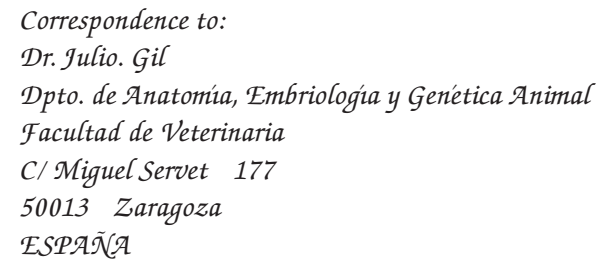

e-mail:juliogi@unizar.es 